\title{
Geodesy by Radio Interferometry: Water Vapor Radiometry for Estimation of the Wet Delay
}

\author{
G. Elgered ${ }^{1}$ J. L. Davis, T. A. Herring,${ }^{2}$ and I. I. Shapiro
}

Harvard-Smithoonian Center for Astrophysics, Cambridge, Massachusetts

\begin{abstract}
An important source of error in very-long-baseline interferometry (VLBI) estimates of baseline length is unmodeled variations of the refractivity of the neutral atmosphere along the propagation path of the radio signals. We present and discuss the method of using data from a water vapor radiometer (WVR) to correct for the propagation delay caused by atmospheric water vapor, the major cause of these variations. Data from different WVRs are compared with estimated propagation delays obtained by Kalman filtering of the VLBI data themselves. The consequences of using either WVR data or Kalman filtering to correct for atmospheric propagation delay at the Onsala VLBI site are investigated by studying the repeatability of estimated baseline lengths from Onsala to several other sites. The lengths of the baselines range from 919 to $7941 \mathrm{~km}$. The repeatability obtained for baseline length estimates shows that the methods of water vapor radiometry and Kalman filtering offer comparable accuracies when applied to VLBI observations obtained in the climate of the Swedish west coast. For the most frequently measured baseline in this study, the use of WVR data yielded a $13 \%$ smaller weighted-root-mean-square (WRMS) scatter of the baseline length estimates compared to the use of a Kalman filter. It is also clear that the "best" minimum elevation angle for VLBI observations depends on the accuracy of the determinations of the total propagation delay to be used, since the error in this delay increases with increasing air mass. For use of WVR data along with accurate determinations of total eurface pressure, the best minimum is about $20^{\circ}$; for use of a model for the wet delay based on the humidity and temperature at the ground, the best minimum is about $35^{\circ}$.
\end{abstract}

\section{INTRODUCTION}

To correct for the atmospheric propagation delay of radio signals due to water vapor (the "wet delay"), water vapor radiometers (WVRs) have been developed for verylong-baseline interferometry (VLBI) designed for estimation of geodetic parameters. The wet delay, typically less than $13 \%$ of the $\sim 7.7-n s$ propagation delay caused by the "dry" constituents of air, is-due to its variability in space and time-a major source of error in estimates of geodetic parameters such as baseline lengths. In terms of equivalent path length, which we use henceforth, the wet delay is typically less than $300 \mathrm{~mm}$ versus $2300 \mathrm{~mm}$ for the dry delay.

During a 24-hour interval, the root-mean-square (RMS) scatter of the wet delay in the zenith direction due to fluctuations of water vapor can be in excess of $50 \mathrm{~mm}$. The corresponding value for the dry constituents is typically less than $10 \%$ of this value.

WVR data can be treated as a priori information about the wet delay, i.e., information obtained prior to the least squares estimation of site positions and other parameters. Other a priori data are ground measurements of humidity and temperature that can be used with a model to predict the wet delay. Because of the unpredictable mixing of wet and dry air and its variability in time the accuracy of this

\footnotetext{
${ }^{1}$ Now at Onsala Space Observatory, Chalmers University of Technology, Onsala, Sweden.

${ }^{2}$ Now at Massachusetts Institute of Technology, Cambridge.

Copyright 1991 by the American Geophysical Union.
}

Paper number 90JB00834.

0148-0227/91/90JB-00834\$05.00 type of model is expected to be too poor to be useful for our application. For comparison, however, we do use a model of this type [Saastamoinen, 1972]; we will refer to it as the ground-based model.

Ideally, we would like to estimate the wet delay with an uncertainty much less than $10 \mathrm{~mm}$, which is the present typical uncertainty of the VLBI group-delay data. It appears that there is no practical possibility for achieving this level of accuracy other than by use of a remote sensing instrument, such as the WVR. However, it is also possible to estimate a correction to a priori propagation delays simultaneously with estimating geodetic and other parameters from the VLBI data. For example, we can estimate a mean zenith bias for an entire observing session or values of samples of, say, an assumed random (Markov) process [Herring et al., 1990] representing the wet delay.

This paper addresses the utility of WVRs in geodetic VLBI experiments. The experiments analyzed here all consist of dual-frequency ( $S$ and $X$ ) band observations. The experiment setup and the data flow are described by Clark et al. [1985]. Before giving our results, we provide a general background discussion of atmospheric propagation delays and water vapor radiometry. Thereafter, we describe the different WVRs that have been used to collect the data we analyzed. The results are presented in two ways. First, we compare the inferred wet delay variations from the WVR to estimates obtained from a Kalman filter for several experiments. Second, we compare the repeatability of estimated baseline lengths obtained using different methods to correct for the atmospheric propagation delays. Since the longest time span of WVR data associated with geodetic VLBI experiments was obtained at the Onsala Space Observatory in Sweden, we present series of estimates of lengths of baselines from Onsala to other sites in the United States and Europe. 


\section{The atmospheric Propagation Delay AND WATER VAPOR RADIOMETRY}

The propagation delay through the neutral atmosphere can be written as the sum of two terms [Davis et al., 1985]. The first is called the "hydrostatic" (or "dry") delay. Its value $\Delta L_{h}$ in the zenith direction, expressed in millimeters, is

$$
\Delta L_{h}=(2.2779 \pm 0.0024) \frac{P_{\circ}}{f(\Phi, H)}
$$

where $P_{0}$ is the total pressure at the ground in millibars and where

$$
f(\Phi, H)=(1-0.00266 \cos 2 \Phi-0.00028 H)
$$

is used to model the variation of the acceleration due to gravity with latitude $\Phi$ and the height of the station $H$, in kilometers, above the (international) ellipsoid, although the results are not sensitive to the differences between the various modern ellipsoids. The uncertainty given for the hydrostatic delay is the root sum square of the effects on it of the uncertainties in (1) the laboratory measurements of the refractivity of dry air [Boudouris, 1963], $2.4 \mathrm{~mm}$; (2) the acceleration due to gravity, $0.2 \mathrm{~mm}$; (3) the universal gas constant, $0.1 \mathrm{~mm}$; and (4) the variability of the dry mean molar mass, $0.1 \mathrm{~mm}$ (see Davis et al. [1985] for details). Effects of departures from hydrostatic equilibrium are, however, not included in this uncertainty (see, for example, Hauser [1989]).

In (1), the constant and its uncertainty differ from those given in Davis et al. [1985] (2.2768 \pm 0.0005$)$ because different constants for the refractivity of dry air were used. Davis et al. used the value from Thayer [1974], derived from an extrapolation from the optical formula: $77.604 \pm$ $0.0014 \mathrm{~K} \mathrm{mbar}^{-1}$. Here, we use the experimentally determined microwave value of Boudouris [1963]: $77.64 \pm$ $0.08 \mathrm{~K} \mathrm{mbar}^{-1}$. Although this latter value is less precise, it does not rely on assumptions of the frequency dependence of the dry refractivity.

The dependence of the hydrostatic delay on elevation angle is modeled using a "mapping function," the accuracy of which is improved if other meteorological measurements, such as of the ground temperature, are used (see, for example, Hopfield [1971]). The mapping function we used for the hydrostatic delay in this study is presented by Davis et al. [1985].

The second term of the total delay is the wet delay $\Delta L_{w}$, which, defined consistently with the hydrostatic delay (1), can be written as

$$
\begin{aligned}
\Delta L_{w}=10^{-6} & {\left[(17 \pm 10) \int_{0}^{\infty} \frac{e}{T} d s\right.} \\
& \left.+(3.776 \pm 0.03) \times 10^{5} \int_{0}^{\infty} \frac{e}{T^{2}} d s\right]
\end{aligned}
$$

expressed in the same units as is the path $s ; T$ is the temperature in kelvins; and $e$ is the partial pressure of water vapor in millibars. The atandard deviations are from the experimental determinations of these constants [Boudouris, 1963]; see Davis et al. [1985] for discussion. This wet delay is determined mainly by the amount of water vapor along the atmospheric path, corresponding to the integration path in (3).
The WVR measures the emission from the sky at two (or more) well-separated frequency bands with one of the bands near the water vapor emission line centered between 22 and $23 \mathrm{GHz}$. The WVR intensity output, for the band closest to the center of this line, will depend on the amount and distribution of water vapor in the direction the WVR antenna is pointed (see (4) below). A second frequency band is needed to correct for emission caused by liquid water, which occasionally can be larger than the vapor contribution even at the center of the water vapor line. Using the Rayleigh-Jeans approximation and the equation of radiative transfer [Chandrasekhar, 1960], we can write the sky brightness temperature measured by the WVR as

$$
T_{s}=T_{b g} e^{-T_{\infty}}+\int_{0}^{\infty} T(s) \alpha(s) e^{-\tau(\theta)} d s
$$

where $T_{b g}$ is the "background" radiation (i.e., from outside the Earth's atmosphere). In the frequency band relevant to WVRs, $T_{b g}$ is due primarily to the cosmic background radiation. $T(s)$ is the physical temperature of the atmosphere along the path, and $\alpha(s)$ is the (composite) attenuation coefficient due to water vapor, liquid water, and oxygen. The parameter $\tau(s)$ is the corresponding opacity from the ground to the point $s$ :

$$
\tau(s)=\int_{0}^{*} \alpha\left(s^{\prime}\right) d s^{\prime}
$$

When $s$ is equal to infinity, the opacity is written as $\tau_{\infty}$. The attenuation coefficient for each of the atmospheric constituents has a unique frequency dependence, which makes it possible to separate approximately the effects due to oxygen, water vapor, and liquid water. Emission plots have been presented by, for example, Resch [1983] and Liebe [1985].

Examining (3) through (5), it becomes clear that by making some approximations we can formulate several (nonunique) algorithms which will enable us to estimate the wet delay from WVR measurements of sky brightness temperature. It is possible to take many different approaches. Generally, the development of the algorithms assumes that the atmosphere is optically thin at the frequencies used by

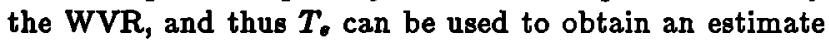
of $\tau_{\infty}$. The opacity, or a similar quantity such as linearized brightness temperature [ $W u, 1979$ ], is then related to wet delay by an integral of the form

$$
\Delta L_{w}=\int_{0}^{\infty} W(s) \alpha(s) d s
$$

where, $W(s)$, the "weighting function", is given by

$$
W(s)=\frac{10^{-6}\left[17 \frac{e}{T}+3.776 \times 10^{5} \frac{e}{T^{2}}\right]}{\alpha(s)}
$$

The ratio

$$
\frac{\int_{0}^{\infty} W(s) \alpha(s) d s}{\int_{0}^{\infty} \alpha(s) d s} \equiv \bar{W}
$$

is the "atmoophere averaged" weighting function. It is $\bar{W}$ which is empirically parameterized in terms of meteorological conditions and which must be optimized for a particular site. Most algorithms do not try to relate the brightness 
temperature at a single frequency to $\Delta L_{w}$, but rather form a linear combination of the brightness temperatures at two frequencies so that the effects of liquid water can be largely removed (see, for example, $W u[1979]$ ). Different wet delay algorithms have been derived by Wu [1979], Resch [1983], Gary et al. [1985], Johansson et al. [1987], and Robinson [1988]. These algorithms are derived for many VLBI sites used, or to be used, in geodetic experiments, and most of them make use of meteorological parameters measured at the ground.

Let us define the "algorithm error" as the error of the wet delay inferred from noise-free radiometer observables. The algorithm error can then be divided into two parts. The first part is due to improperly modeled height profiles of temperature and water vapor; these errors can vary on time scales of hours to days. Depending on the completeness of the parameterization of $\bar{W}$, this error source can be different for different algorithms. For the wet delay algorithms referred to above, the root-mean-square error of this first part, for the zenith direction, varies between 1 and $4 \mathrm{~mm}$, for weather situations excluding rain or heavy rain clouds. The typical rate of change, for the zenith direction, is 1-2 mm per 12 hours. Nevertheless, a few times per year this rate can approach $10 \mathrm{~mm}$ per 12 hours (see references above).

The second part of the algorithm error is due to possible errors in the attenuation coefficients. This part of the error should be common to all algorithms which use the same expressions for the attenuation coefficients. The uncertainty in the attenuation of oxygen is the least important and corresponds to an error in the inferred wet delay in the zenith direction of less than $2 \mathrm{~mm}$. This limit was derived by comparing the results from algorithms of the form described above using different attenuation coeffi- cients for oxygen [Meeks and Lilley, 1963; Snider and Westwater, 1969; Liebe, 1985; Liebe, 1987; Rosenkranz, 1988].

The attenuation due to liquid water is proportional to the square of the frequency [Goldstein, 1951; Staelin, 1966]. This frequency dependence is valid as long as the sizes of the liquid water drops are much smaller than the wavelength of the attenuated signal. For all the WVRs used for geodetic VLBI, the "cloud correction band" is centered at about $31 \mathrm{GHz}$ (wavelength $\approx 10 \mathrm{~mm}$ ). If the sizes of the drops in the atmosphere are not, say, a few tenths of a millimeter or less, i.e., negligible compared with the wavelength, dual-frequency algorithms of the type described will overestimate the wet delay. An example of the effect of large drops is given in Figure 1, where the effect is further increased by the accumulation of water drops on the teflon covers of the horn antennas. Our experience indicates that during rain, WVR data are of no use for the calculation of accurate wet delay corrections.

When it is not raining, the uncertainty in the attenuation due to water vapor appears to be the limiting factor. There are a number of published formulas for this attenuation [Staelin, 1966; Waters, 1976; Liebe, 1985; Liebe, 1987], and a lower bound on the errors in the estimates of $\Delta L_{w}$ obtained by radiometric techniques can be obtained by comparing algorithms derived with different expressions for the water vapor attenuation. Such studies indicate that errors in $\Delta L_{w}$ of $4-6 \%$, with the uncertainty increasing with decreasing temperature, are likely. Even a $4 \%$ error is, however, not negligible. Zenith wet delays of between $100 \mathrm{~mm}$ and $300 \mathrm{~mm}$ are not unusual in the temperate summer. For typical elevation angles of about $30^{\circ}$, we will then obtain errors of the order of 10-30 mm in our estimated wet delay corrections. These errors are large when compared with the uncertainties of current individ-

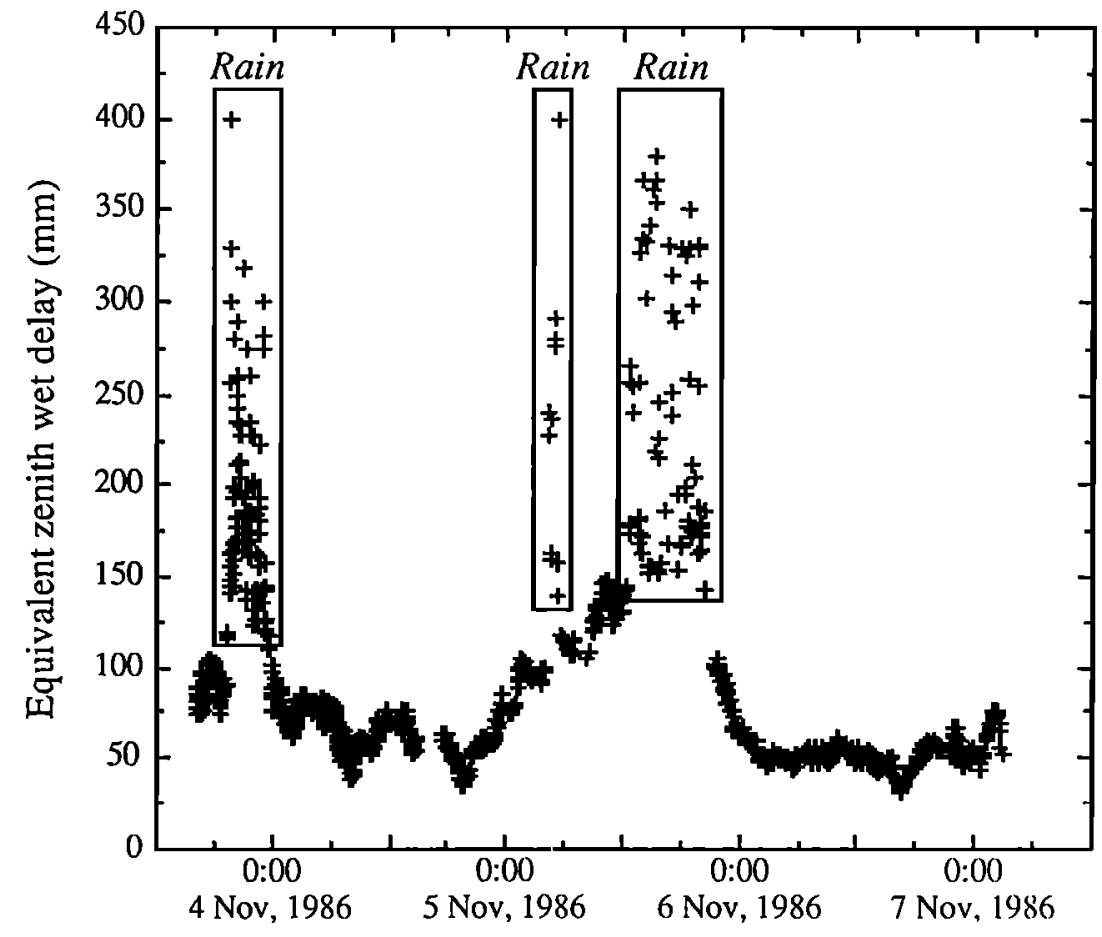

Fig. 1. WVR measurements carried out during 4 days in November 1986. The large errors in the inferred wet delays from WVR data taken during rain is in this case further increased by water drops forming on the covers of the horn antennas. The error bars for the WVR data have been omitted. 
ual VLBI group-delay measurements, which are approximately $10 \mathrm{~mm}$ or less.

\section{BRIEF DESCRIPTION OF WATER VAPOR RADIOMETERS FOR GEODETIC VLBI}

Responsibility for the design and manufacture of WVRs specifically for use in geodetic VLBI experiments was assigned by the National Aeronantics and Space Administration (NASA) in the mid-1970s to the Jet Propulsion Laboratory (JPL) in Pasadena, California, where seven WVRs were subsequently built [Resch et al., 1985]. Independently, at the Onsala Space Observatory in Sweden, one WVR, referred to as ASTRID (Atmospheric Sky Temperature Radiometer for Interferometric Delay corrections), was built [Elgered and Lundh, 1983]. Later, four of the JPL instruments (known as R-series WVRs) were upgraded, and a new more compact (J-series) WVR was made at JPL [Janssen, 1985]. More J-series WVRs are now being built, and another, independently designed, WVR is being built at the Geodetic Institute in Bonn for use at the VLBI station in Wettzell, Federal Republic of Germany [Reichert, 1985].

The different WVRs that have been used in Mark-III VLBI experiments are briefly described in Table 1. System noise temperatures are all about $600 \mathrm{~K}$. The WVRs are all fully steerable in azimuth and elevation, but the slew speeds are quite different. Even though all antennas used for VLBI observations typically slew at $0.5^{\circ}-2^{\circ} \mathrm{s}^{-1}$, it is an advantage to have a higher slewing speed for the WVR. The WVR measures sky brightness temperatures by comparing its power output when looking at the sky with the output obtained when looking at reference loads (and/or noise diodes) of known temperature. These comparisons are used to determine the (designed) linear relationship between power output and radiometric temperature, which is then used to convert output power from the sky to sky brightness temperature. In addition, owing to losses and reflections in the waveguides, it is necessary to estimate a correction to that reference load which is not at ambient temperature (or a correction to the radiometric temperature of a noise diode). This correction is determined by performing an elevation scan, or "tip curve," which uses the fact that at zero air mass the brightness temperature equals $T_{b_{0}}$ of (4) [Dicke et al., 1946]. This procedure is more successful if the WVR slews sufficiently quickly to allow time between the VLBI observations for making tip curves.

The tip curve method is sensitive to any inhomogeneities in the atmosphere, but, provided that tip curves are carried out at different azimuth angles, errors due to gradients tend to average out. If the atmosphere is very inhomogeneous, which is often the case when significant amounts of liquid water are present, the noise in the tip curve data becomes very apparent, and the data can be downweighted before using them in the calibration procedure.

\section{INFERRING WET DELAYS FROM WVR DATA AND FROM A KALMAN FILTER}

When a Kalman filter is used to estimate the atmospheric delay [Herring et al., 1990], the normal procedure is to use the measured ground pressure to calculate the hydrostatic delay using (1) and (2) and to estimate an additional propagation delay which is then assumed to be equal to the wet delay. The wet delay estimated using the Kalman filter will therefore have, in addition to the uncertainty arising from noise in the VLBI data and errors in the VLBI models, an uncertainty arising from errors in the inferred hydrostatic delay. Since the water vapor has a different distribution with height than has the dry air, a special "wet mapping function" must be used to calculate the partial derivatives in the estimation process. A mapping function for the elevation dependence of the wet delay presented by Chao [1972] was used in this analysis. Details of the analysis techniques are discussed by Herring et al. [1990].

We have compared the two methods-Kalman filter and WVR-for different sites involving different WVRs. Figures 2-4 show the equivalent zenith wet delay inferred from WVR data and estimated, using the Kalman filter technique, from the VLBI data themselves. The error bars for the WVR data have been omitted. They vary, mainly as a function of the elevation angle of the observation, between 5 and $8 \mathrm{~mm}$ for the old R-series WVR and between 2 and $4 \mathrm{~mm}$ for the other instruments. In addition to these random errors, there are biases in the measurements and in the inversion algorithm, both of which contribute to the overall uncertainty of the WVR-inferred wet delays. The error bars for the VLBI estimates do not account for errors

TABLE 1. Water Vapor Radiometers Used in the Mark-III VLBI Experiments

\begin{tabular}{|c|c|c|c|c|c|c|c|c|c|}
\hline \multirow[b]{2}{*}{ Frequencies, GHz } & \multicolumn{2}{|c|}{ R Series } & \multicolumn{2}{|c|}{ New R Series } & \multicolumn{3}{|c|}{ J Series } & \multicolumn{2}{|c|}{ ASTRID } \\
\hline & 20.7 & 31.4 & 20.7 & 31.4 & 20.7 & 22.2 & 31.4 & 21.0 & 31.4 \\
\hline $\begin{array}{l}\text { Antenna } \\
\text { beam width, deg }\end{array}$ & 7 & 7 & 7 & 7 & 9 & 9 & 7 & & 6 \\
\hline $\begin{array}{l}\text { Reference load } \\
\text { temperatures, } K \\
\text { RF bandwidth. }\end{array}$ & \multicolumn{2}{|c|}{$313 / 413$} & \multicolumn{2}{|c|}{$313 / 413$} & \multicolumn{3}{|c|}{$\begin{array}{c}313+ \\
\text { noise diode }\end{array}$} & \multicolumn{2}{|c|}{$\begin{array}{l}77 / 313 \text { or } \\
313 / 360^{a}\end{array}$} \\
\hline MHz & \multirow{2}{*}{\multicolumn{2}{|c|}{$\begin{array}{c}200 \\
10-110\end{array}$}} & \multirow{2}{*}{\multicolumn{2}{|c|}{$\begin{array}{c}200 \\
10-110\end{array}$}} & \multirow{2}{*}{\multicolumn{3}{|c|}{$\begin{array}{c}320 \\
40-200\end{array}$}} & \multirow{2}{*}{\multicolumn{2}{|c|}{$\begin{array}{c}990 \\
5-500\end{array}$}} \\
\hline $\begin{array}{l}\text { IF band, MHz } \\
\text { Slewing speed }\end{array}$ & & & & & & & & & \\
\hline $\mathrm{AZ}, \mathrm{EL}, \mathrm{deg} / \mathrm{B}$ & \multicolumn{2}{|c|}{$1.5,1.5$} & \multicolumn{2}{|c|}{$7.5,6.6$} & \multicolumn{3}{|c|}{12,60} & \multicolumn{2}{|c|}{$1.7,1.7$} \\
\hline
\end{tabular}

See text for description of different WVR designs.

"Referred to as "cold" or "hot" mode. The WVR was running in hot mode during six of the 119 experiments analyzed in this study. In hot mode the RMS noise in the estimated wet delay is about $5 \mathrm{~mm}$, compared with $3 \mathrm{~mm}$ in cold mode. 


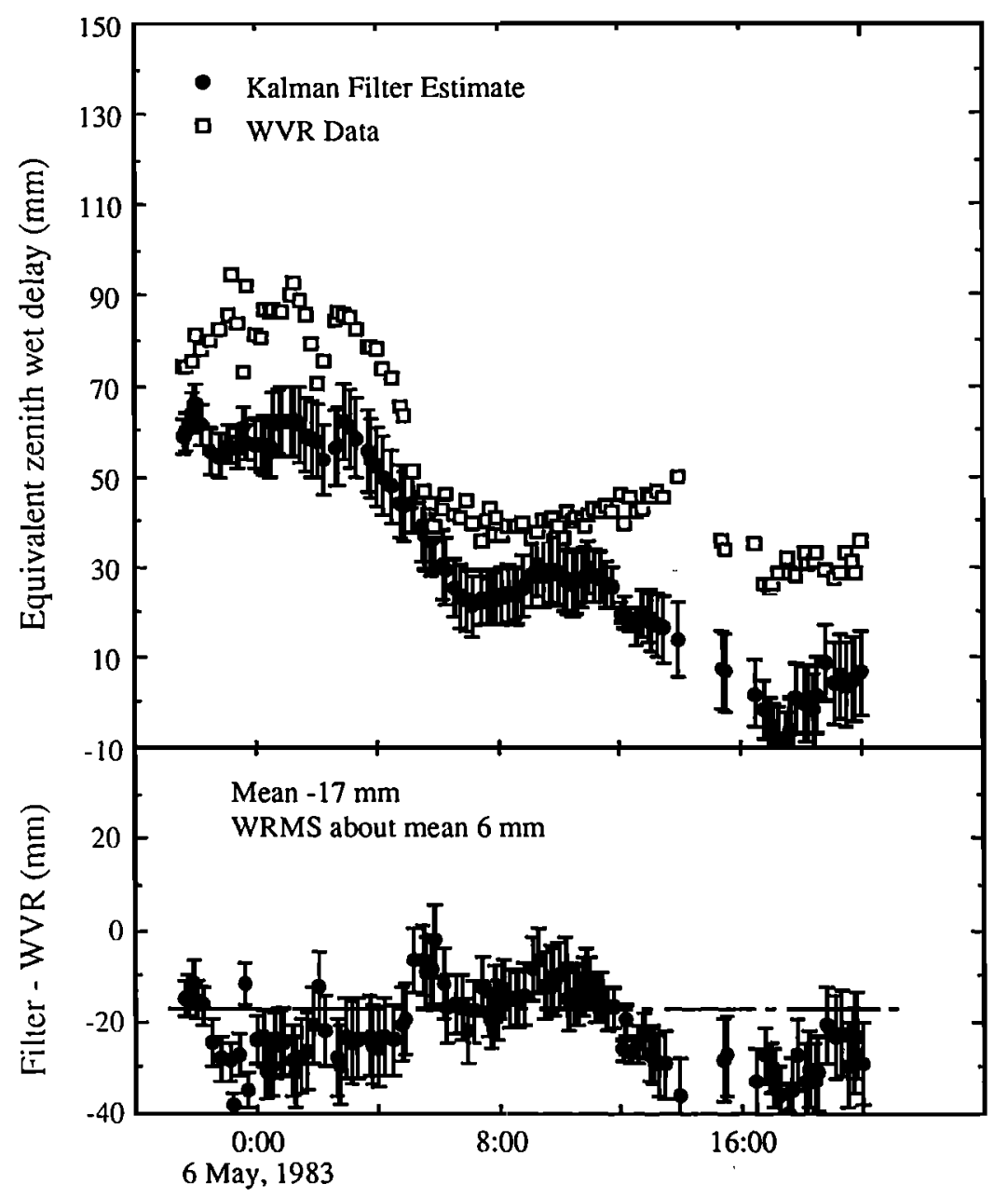

Fig. 2. WVR measurements and Kalman filter estimates, for the same epochs, of the equivalent zenith wet delay at the Haystack Observatory. An old R-series WVR was used.

in the hydrostatic zenith (neither the zenith value nor the mapping function).

In Figure 2, the WVR data are from the old R-series used at the Haystack Observatory, Massachusette; Figure 3 shows the same type of comparison for an upgraded R-series WVR at the Mojave site, located in the Mojave desert in California. Figure 4 shows the result from three contiguous observing sessions: one "Atlantic" experiment within NASA's Crustal Dynamics Project (CDP) [Coates et al., 1985], including antennas at Westford (Massachusetts), Onsala (Sweden), and Wettzell (Federal Republic of Germany); one "IRIS" (International Radio Interferometric Surveying [Carter et al., 1985]) experiment, including antennas at Westford, Fort Davis (Texas), Richmond (Florida), Onsala, and Wettzell; and one "Polar" (CDP) experiment, including antennas at Kashima (Japan), Fairbanks (Alaska), Mojave (California), Westford, Onsala, and Wettzell.

\section{ON THE ACGURAGY OF THE ESTIMATED PROPAGATION DELAY}

In each of the comparisons shown in Figures 2-4, both sets of estimates often exhibit similar short-term variations for the wet delay, but with an apparent long-term bias. We have studied the biases obtained for the Onsala site using a set of 119 Mark-III VLBI experiments in which WVR and VLBI data are both available at the Onsala site for more than approximately half of each experiment. These experiments were carried out between July 1980 and June 1988. The WVR data were used with the algorithm presented by Johansson et al. [1987] for estimating the wet delay. We used ground pressure measurements together with the WVR data to determine the propagation delays at Onsala, but in the least squares analysis we estimated one constant correction to the equivalent propagation delay in the zenith direction for each experiment. At all other sites the atmospheric propagation delays were estimated by assuming that these propagation delays could be represented by a random walk stochastic process. The clocks at all sites were estimated using a combined random walk and integrated random walk stochastic process [Herring et al., 1990]. The statistical parameters of the Markov process used for estimation of the atmospheric propagation delay were obtained from previous analyses of the rate residuals for each experiment [Herring et al., 1990]. Ideally, the estimate of this additional propagation delay in the zenith direction would be zero for each experiment. However, several sources of error will influence the result. Below, the estimates of these errors are given as "root-mean-square" 


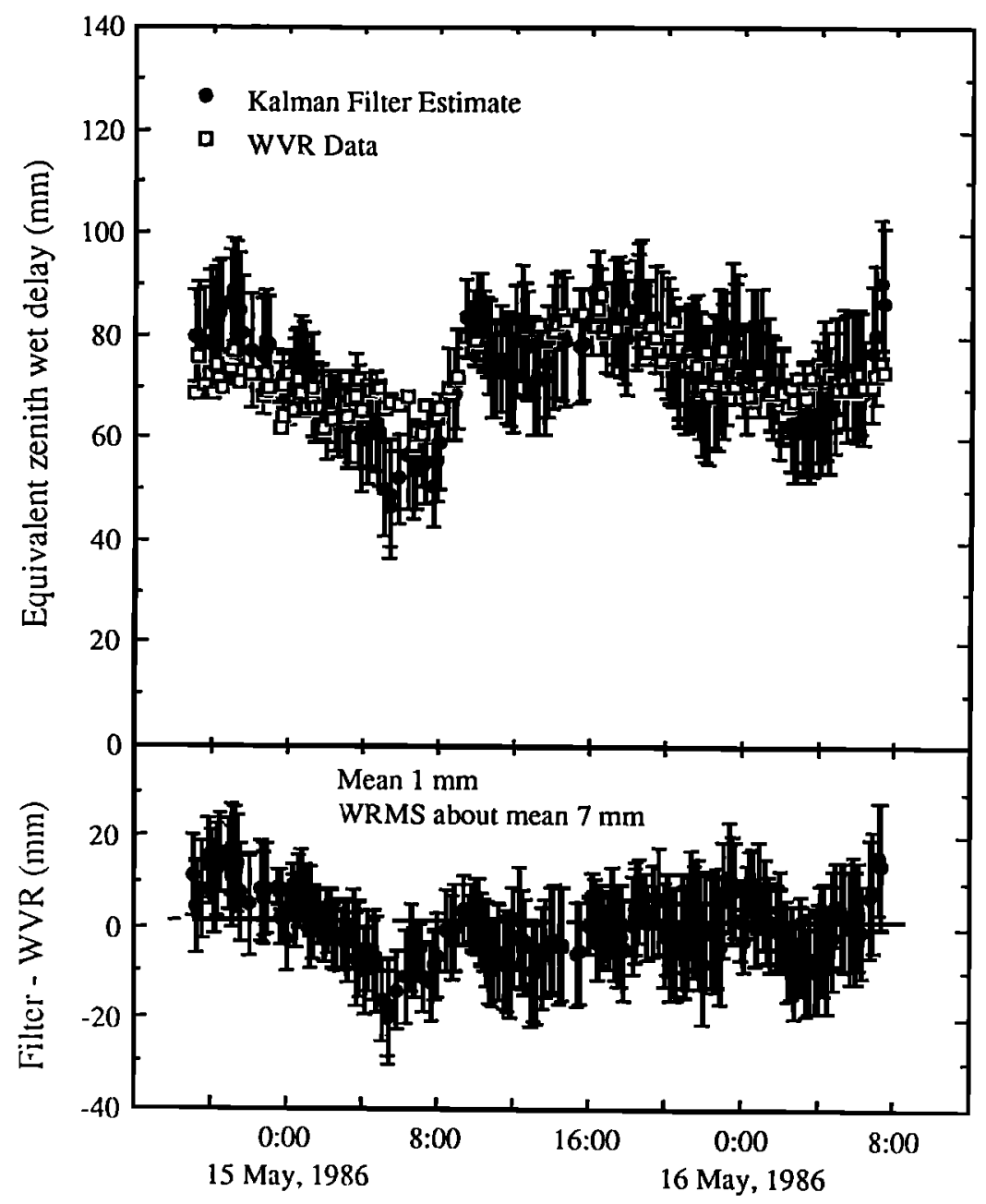

Fig. 3. WVR measurements and Kalman flter estimates, for the same epochs, of the equivalent zenith wet delay at the Mojave VLBI site. A new R-series WVR was used.

and "bias" for a 24-hour period in each relevant case. The signs of the biases are unknown; their magnitudes are inferred approximately from the spread in published values or from experimental evidence.

1. Error in the inversion algorithm used with the WVR data, due to approximations of the atmospheric profiles of pressure, temperature, and humidity: $2 \mathrm{~mm}$ RMS in the zenith direction for the algorithm used with this data set [Johansson et al., 1987].

2. Error in the inversion algorithm used with the WVR data, due to uncertainties in the attenuation coefficients of water vapor: a bias of approximately $4-6 \%$ of the wet delay (see above).

3. WVR instrumental error, averaged over 24 hours: RMS 2-3 mm, bias up to $10 \mathrm{~mm}$.

4. Uncertainty of the wet refractivity constants in equation (3): bias of $1 \%$ of the wet delay [Boudouris, 1963].

5. Error in the total pressure measurement at Onsala: 1 mbar, corresponding to $2 \mathrm{~mm}$ in equivalent zenith propagation delay. This error manifests itself as a bias during a single experiment but could vary over time scales of months as determined by comparison of Onsala's barometer with those of nearby ( $<40 \mathrm{~km}$ distant) meteorological stations.

6. Uncertainty in equation (1) for the hydrostatic delay: bias of $0.1 \%$, corresponding to $2 \mathrm{~mm}$ in equivalent zenith propagation delay.
7. Violation of hydrostatic equilibrium in the atmosphere [Hauser, 1989]. Such errors should be important (larger than $1 \mathrm{~mm}$ in equivalent zenith propagation delay) only when very strong winds exist [Holton, 1979]. In this data set, before March 1987 , there are no data taken at Onsala when the wind exceeded $13 \mathrm{~m} \mathrm{~s}^{-1}$ at the ground because of a wind speed limit for antenna operation. However, this surface wind speed condition does not exclude the possibility that high-altitude winds affect our results.

8. Any unmodeled, or improperly modeled, effect in the VLBI data which could affect the estimate of the excess propagation delay.

9. Errors in the mapping functions. The hydrostatic mapping function which is used to map the hydrostatic (or dry) delay from the zenith direction to the elevation angle of the observation: RMS at $10^{\circ}$ elevation angle is about $10 \mathrm{~mm}$, which projects through our estimator to yield approximately $5 \mathrm{~mm}$ RMS errors in the estimated zenith wet delay. The error in the wet mapping function is believed to be of the same magnitude. As an experiment we used mapping functions derived from radiosonde profiles obtained at Göteborg-Landvetter airport, $37 \mathrm{~km}$ from Onsala, for the three VLBI observing sessions presented in Figure 4. This technique reduced the mean difference apparent in Figure 4 by about $5 \mathrm{~mm}$. (These reduced differences are not shown.) We did not use radiosonde-derived 


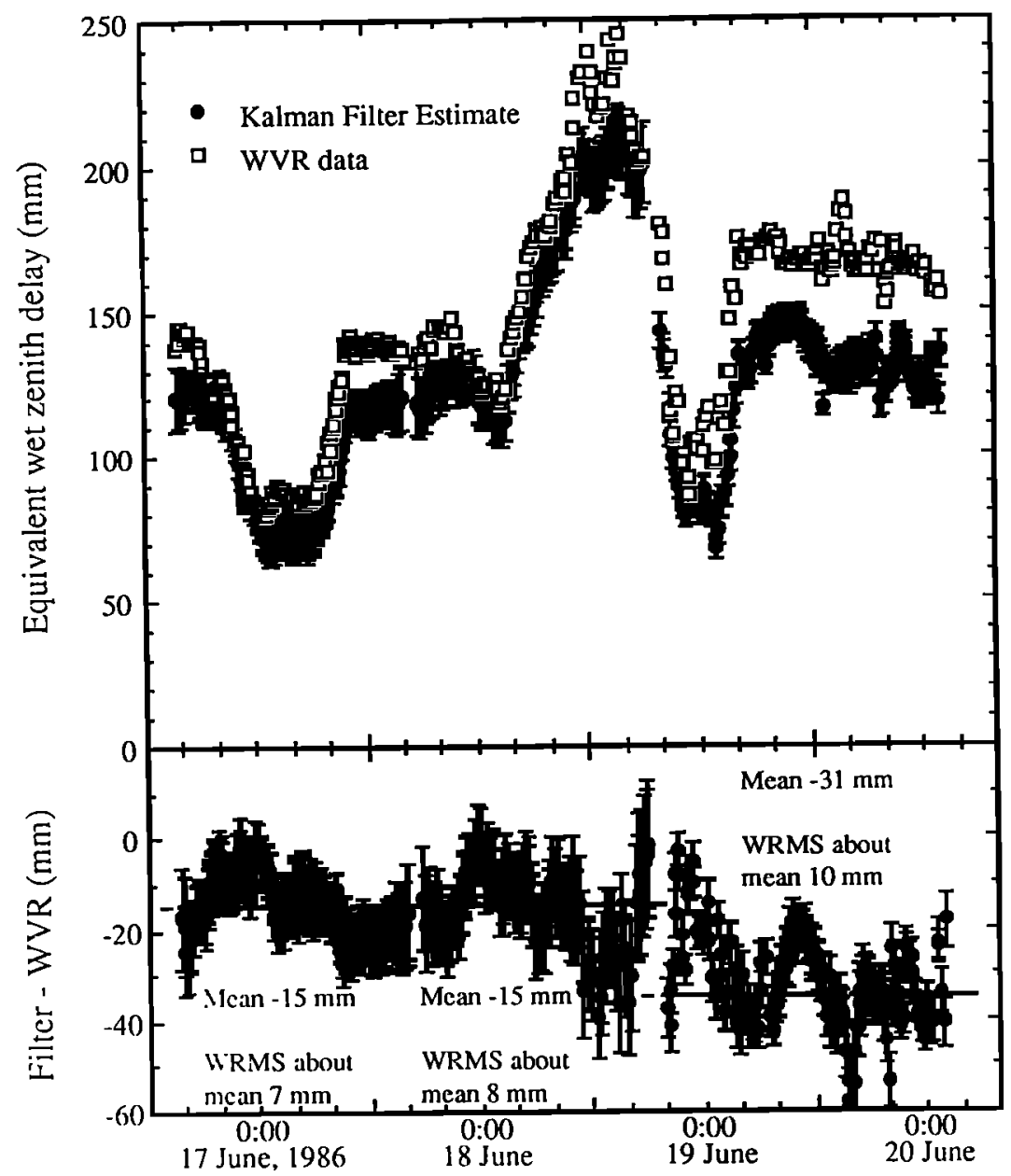

Fig. 4. WVR measurements and Kalman filter estimates, for the same epochs, of the equivalent zenith wet delay at the Onsala Space Observatory. The ASTRID WVR was used. Each 24-hour observing session of the 3-day experiment was processed and is shown separately. There was no constraint placed to ensure continuity of the estimates for successive sessions.

mapping functions for any of the other results presented in this paper.

Three sets of solutions are presented in Figure 5. Each solution uses a different minimum (cut-off) elevation angle for the observations made at Onsala. The effect of an error in the mapping function is expected to be larger at low elevations, which should be reflected in the estimated mean bias. Of course, the uncertainty of the estimated zenith bias increases rapidly with increasing cut-off angle. We obtain a rather large uncertainty $(2.3 \mathrm{~mm})$ for the mean of the estimated biases for a $25^{\circ}$ cut-off in elevation angle. This fact, together with there being no significant difference in the mean biases obtained in the first two solutions (no cut-off and $15^{\circ}$ cut-off), implies that it is not possible to explain the bias solely in terms of errors in the mapping functions.

The errors associated with the estimates of wet delay are primarily fractional errors and cannot alone explain the results in Figure 5: a distinguishable bias of about $10 \mathrm{~mm}$ virtually constant with time. Fractional errors will cause the estimates of the wet delay to have errors which increase in the summer, when the wet delay is large, and decrease in the winter. However, an instrumental bias of the WVR could be at least partly responsible. To address the issue of instrumental biases, side-by-side comparisons of ASTRID (Table 1) and a new J-series radiometer (J03 ) were made at Onsala in June and July 1988, in an experiment organized by the Onsala Space Observatory and NASA Goddard Space Flight Center. A preliminary analysis of a subset of these data (obtained with ASTRID operating in cold mode) indicates that the daily biases between ASTRID and J-03 varied between 0 and $10 \mathrm{~mm}$, with a mean of $3 \mathrm{~mm}$.

Another source of error that deserves comment is the uncertainty in the observed total ground pressure. The observed pressures at the Onsala site used in this data set have been compared to the results from other pressure sensors in the area and corrected, when necessary. Thereafter, the pressure was referred to the height at which the signals are referenced within the radio telescope. We believe this procedure has resulted in an uncertainty of the pressure measurements of about 1 mbar, corresponding to an equivalent zenith propagation delay standard error of about $2 \mathrm{~mm}$.

Finally, the combination of several of the errors discussed above could sum up to the observed 10 -mm bias in the estimated zenith propagation delay. Hence the overall bias can be reduced significantly only by reducing the size of many of the individual sources of error described above. 


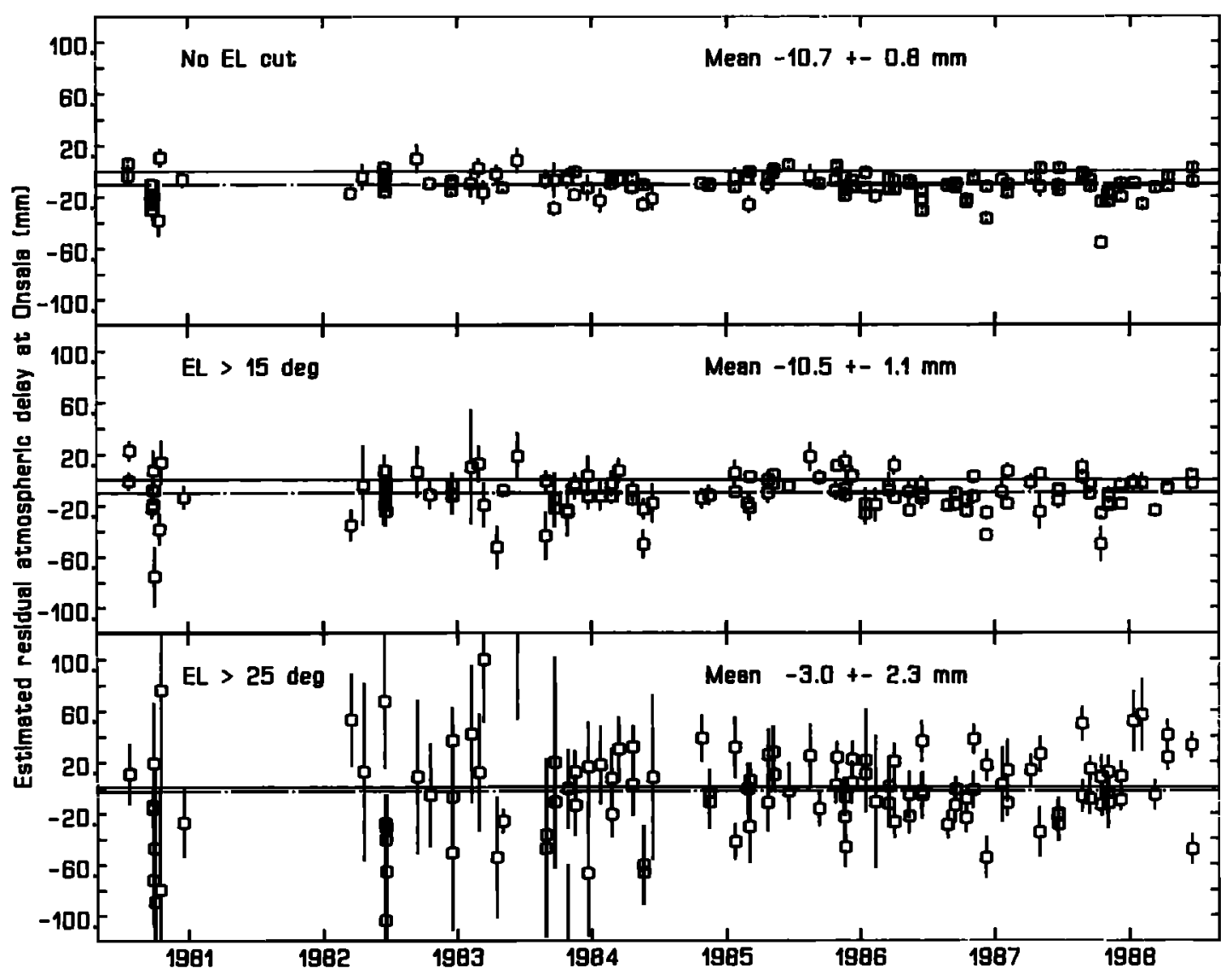

Fig. 5. Estimated values of a constant (zenith) atmospheric delay correction for Onsala, using an a priori propagation delay consisting of the hydrostatic delay calculated from the total ground pressure and the wet delay inferred from WVR data. The estimation was done three times for 119 VLBI experiments, each of the three times with a different elevation cut-off angle at Onsala in order to check the sensitivity of the estimated value for mapping function errors. The uncertainties for the averages are calculated using the standard deviations for individual determinations, scaled by the square root of the reduced $\chi^{2}$ of the residual values.

USING WVR DATA AND

\section{LOW Elevation ANGLE OBSERVATIONS}

Low elevation angle observations are not important unless atmospheric propagation delay corrections are estimated [Herring, 1986] and can actually degrade the accuracy of the (other) estimated parameters (1) if there are mapping function errors or (2) if there are zenith delay errors and no zenith delay correction is being estimated.

Independent of the sources of the bias discussed in the previous section, it is important to study the resulting repeatability of estimated baseline lengths for different elevation cut-off angles when no atmospheric propagation delays are estimated for the sites that have WVRs. Some results are shown in Figure 6, where again the set of 119 experiments involving WVR data at Onsala is used. For each set of solutions made, for a given elevation cut-off angle, the WRMS scatter of baseline lengths about the estimated slope is presented. The WRMS value is used as a measure of repeatability. In these solutions no atmospheric parameters are estimated, and there is a small improvement in repeatability for all baselines (excluding Onsala-Haystack) as we raise the elevation cut-off angle. The effect is larger for the longer baselines, since the error made in the local vertical coordinate affects the baseline length more in these cases. Although the optimum cut-off angle is not identical for the different baselines, a value of $20^{\circ}$ seems reasonable for all cases. For all of the WVRs in Table 1 an elevation angle of $20^{\circ}$ is approximately the lowest that can be used without picking up ground noise.

To show the cut-off effect more clearly, we have used the ground-based model instead of the WVR data and presented the results in Figure 7. The expected uncertainty accompanying the use of this model, averaged over a year, is about $20 \mathrm{~mm}$ RMS in equivalent zenith propagation delay for the Swedish west coast climate [Elgered and Lundquist, 1984]. The main part of this error will show up as a bias during a 24-hour observing session. In this case an elevation cut-off angle of about $35^{\circ}$ is recommended. Note that the data deleted in this study are only those for observations made below the elevation angle cut-off at Onsala. If the cut-off criterion had been applied at other sites as well, we would have had a much larger data loss, especially for the long baselines, implying a more rapid increase of the WRMS for higher cut-off angles.

\section{REPEATABILITY OF ESTIMATED BASELINE LENGTHS: COMPARISONS BETWEEN USE OF WVR DATA AND KaLMaN FILTERING}

The set of 119 experiments was analyzed several more times, each time with.a different method used to correct for 


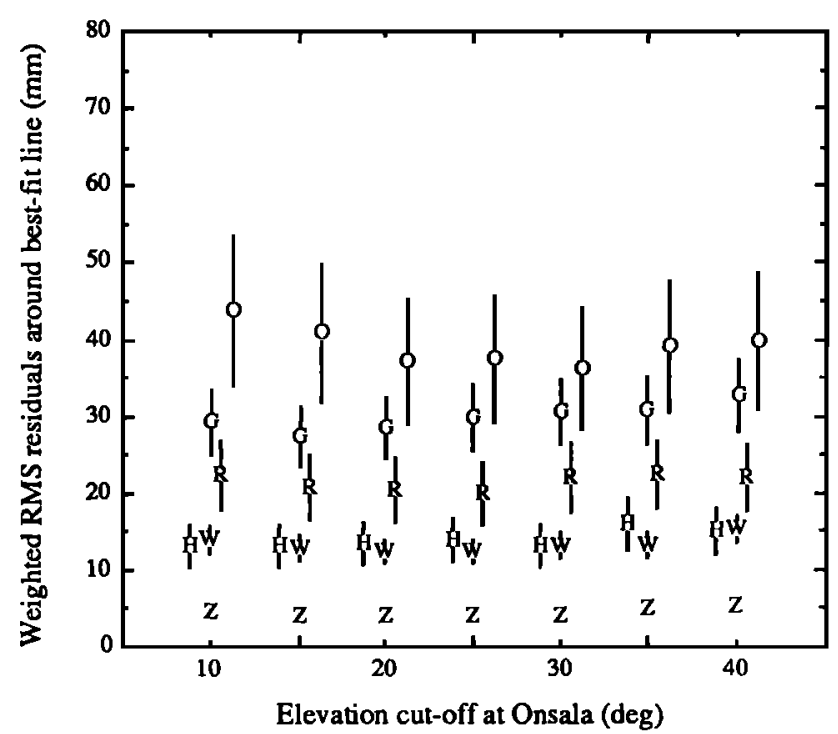

Fig. 6. WRMS residuals of estimated baseline lengths about a "best fit" straight line, as a function of cut-off angle. The error bar shows the $90 \%$ confidence interval. The hydrostatic delays and the WVR data constitute the a priori information used; no estimate of the atmospheric delay at Onsala was made. Seven sets of solutions were made, each with a different elevation cutoff angle at Onsala. The baselines are from Onsala to: Wettzell (Z, 919 km, 72 experiments), Haystack (H, 5600 km, 30 experiments), Westford ( $W, 5601 \mathrm{~km}, 96$ experiments), Richmond ( $R$, $7307 \mathrm{~km}, 32$ experiments), OVRO (O, 7914 km, 28 experiments) and GRAS (G, $7941 \mathrm{~km}, 73$ experiments). See Table 2 footnotes for explanation of site name abbreviations.

the wet delay at Onsala, but with the atmospheric propagation delays for all other sites, as well as the clocks for all sites, modeled as Markov processes.

The estimated mean rates of change of the baselines from these analyses are presented in Table 2 as are all the WRMS scatters about these slopes. The WRMS scatters for the different solutions are presented graphically in Figure 8. Based on the results presented in Figures 6 and 7 , an elevation cut-off angle was applied for Onsala data when either (1) WVR data were used to estimate the wet delay, or (2) the ground-based model for the wet delay was used and no estimates were made for the atmospheric propagation delay at Onsala. The repeatability obtained is about the same in all cases which involve either the use of WVR data as a priori information or the estimation of the atmospheric propagation delays based on their being a Markov process. The differences of the estimated rates are small compared with their uncertainties, which may be estimated by taking the square root of the differences of the variances of each of the rates comprising the difference. (This approximation is inexact only because we scale the standard deviations of the estimated slopes as described in the caption to Figure 5.)

For two of the baselines examined (Onsala-OVRO and Onsala-Haystack), it appears to be better to estimate a constant correction to the zenith propagation delay inferred from the WVR data than to discard low-elevation observations. In the case of Onsala-Haystack, we know from Figure 6 that inclusion of the low-elevation data actually yielded a lower WRMS, even with no atmospheric bias estimated. Note that the $90 \%$ confidence intervals are relatively large for these two baselines and that they were based on more data from earlier epochs than were the other baselines (see the mean epochs given in Table 2). The quality of WVR data, as well as that of VLBI data, has improved since 1980.

The change of accuracy of the data with time is further illustrated in Figure 9, where we have combined all the results from Onsala to Haystack and to Westford. Note that either Haystack or Westford or both have been involved in all the 119 experiments analyzed in this paper. The WRMS residual about the "best fit" slope for the last 37 experiments (August 1986 to June 1988) is $9.8 \mathrm{~mm}$ when the WVR data are used and $12.0 \mathrm{~mm}$ when, instead, the wet delays are estimated.

To understand better the differences between the solutions with and without the WVR data used, we have compared the estimates of the coordinates of Onsala for the two types of solution shown in Figure 9. We will refer to these as the Markov and WVR solutions. In general, studies of station coordinates are complicated by our uncertain knowledge of Earth rotation parameters. To avoid the complications of (1) introducing interpolation errors and (2) including effects of correlations between the Earth rotation parameters (which are largely determined by VLBI data) and our data, we chose to restrict our data set to those experiments which included Wettzell and at least two other sites. The positions of Onsala were then determined in a coordinate system defined by the other sites in the network, whose three-dimensional velocities relative to North America were determined previously by a global solution using all of our VLBI data. These other sites were moved as a function of time so that the coordinate system they defined remained fixed relative to North America. The 54 estimates of Onsala's position in its local north, east and up coordinate system are shown in Figure 10 for the Markov and WVR solutions. The WRMS scatters of the results from these two solutions are very similar for each component. In particular, for the Markov solution, the WRMS scatter of the north component, which is the component

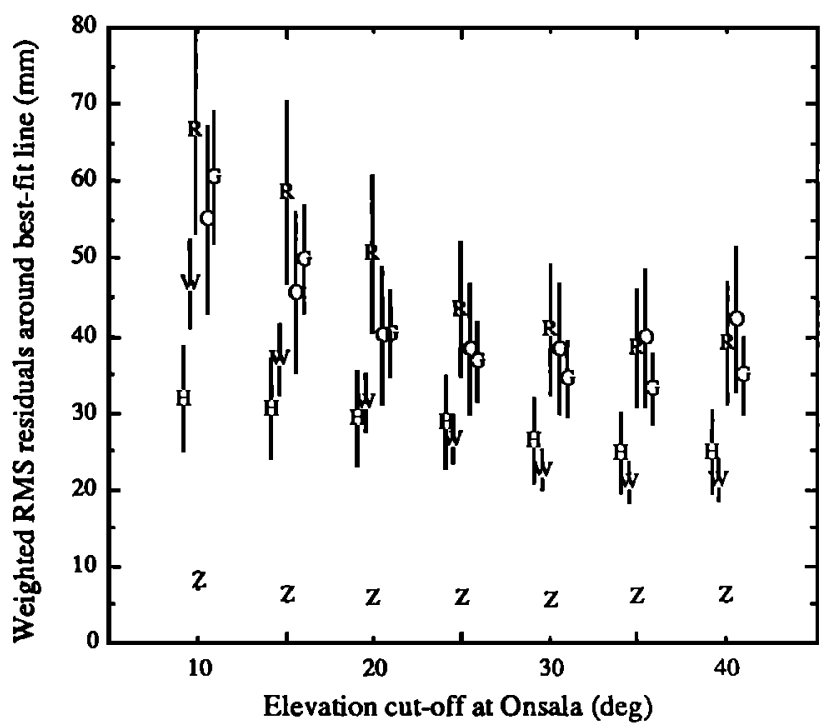

Fig. 7. WRMS residuals of estimated baseline lengths about a "best fit" straight line as a function of cutoff angle. The hydrostatic delay and the ground-based model constitute the a priori information used; no estimate of the atmospheric delay at Onsala was made. For the baseline code, see the caption to Figure 6 . 
TABLE 2. Bageline Length Repeatability

\begin{tabular}{|c|c|c|c|c|}
\hline \multirow{2}{*}{$\begin{array}{l}\text { Baseline:a } \\
\text { Onsala } \\
\text { to }\end{array}$} & \multicolumn{2}{|c|}{$\begin{array}{l}\text { Method Used to Correct for } \\
\text { the Wet Delay at Onsala }\end{array}$} & \multirow[t]{2}{*}{$\begin{array}{l}\text { Slope, }_{-1}^{c} \\
\text { mm yr }^{-1}\end{array}$} & \multirow{2}{*}{$\begin{array}{c}\text { Weighted RMS } \\
\text { About Slope, } \\
\text { mm }\end{array}$} \\
\hline & A priori & Adjustment & & \\
\hline $\begin{array}{l}\text { Wettzell } \\
\text { (72 experiments, } \\
919 \mathrm{~km} \text {, mean } \\
\text { epoch 1987.0) }\end{array}$ & $\begin{array}{l}\text { None } \\
\text { None } \\
\text { Model }\left(35^{\circ}\right) \\
\text { Model } \\
\text { Model } \\
\text { WVR }\left(20^{\circ}\right) \\
\text { WVR } \\
\text { WVR }\end{array}$ & $\begin{array}{l}\text { Bias } \\
\text { Markov } \\
\text { None } \\
\text { Bias } \\
\text { Markov } \\
\text { None } \\
\text { Bias } \\
\text { Markov }\end{array}$ & $\begin{array}{l}-2.1 \pm 0.5 \\
-1.9 \pm 0.4 \\
-2.4 \pm 0.7 \\
-2.4 \pm 0.5 \\
-1.8 \pm 0.4 \\
-1.6 \pm 0.4 \\
-1.4 \pm 0.5 \\
-1.6 \pm 0.4\end{array}$ & $\begin{array}{l}5.1 \\
4.1 \\
6.3 \\
4.8 \\
4.3 \\
4.0 \\
4.4 \\
4.2\end{array}$ \\
\hline $\begin{array}{l}\text { Haystack } \\
\text { (30 experiments, } \\
5600 \mathrm{~km} \text {, mean } \\
\text { epoch 1984.0) }\end{array}$ & $\begin{array}{l}\text { None } \\
\text { None } \\
\text { Model }\left(35^{\circ}\right) \\
\text { Model } \\
\text { Model } \\
\text { WVR }\left(20^{\circ}\right) \\
\text { WVR } \\
\text { WVR }\end{array}$ & $\begin{array}{l}\text { Bias } \\
\text { Markov } \\
\text { None } \\
\text { Bias } \\
\text { Markov } \\
\text { None } \\
\text { Bias } \\
\text { Markov }\end{array}$ & $\begin{array}{l}14.5 \pm 1.3 \\
15.2 \pm 1.2 \\
14.7 \pm 2.3 \\
12.0 \pm 1.8 \\
15.4 \pm 1.2 \\
16.3 \pm 1.3 \\
14.6 \pm 1.2 \\
15.4 \pm 1.3\end{array}$ & $\begin{array}{l}14.1 \\
12.1 \\
24.8 \\
18.5 \\
11.3 \\
13.3 \\
11.5 \\
12.0\end{array}$ \\
\hline $\begin{array}{l}\text { Westford } \\
\text { (96 experiments, } \\
5601 \mathrm{~km} \text {, mean } \\
\text { epoch 1986.8) }\end{array}$ & $\begin{array}{l}\text { None } \\
\text { None } \\
\text { Model }\left(35^{\circ}\right) \\
\text { Model } \\
\text { Model } \\
\text { WVR }\left(20^{\circ}\right) \\
\text { WVR } \\
\text { WVR }\end{array}$ & $\begin{array}{l}\text { Bias } \\
\text { Markov } \\
\text { None } \\
\text { Bias } \\
\text { Markov } \\
\text { None } \\
\text { Bias } \\
\text { Markov }\end{array}$ & $\begin{array}{l}11.6 \pm 1.6 \\
12.9 \pm 1.0 \\
12.0 \pm 1.5 \\
11.2 \pm 1.4 \\
12.8 \pm 1.0 \\
13.3 \pm 0.9 \\
13.3 \pm 1.1 \\
13.5 \pm 1.0\end{array}$ & $\begin{array}{l}20.9 \\
13.9 \\
20.8 \\
19.0 \\
13.7 \\
12.3 \\
14.6 \\
14.0\end{array}$ \\
\hline $\begin{array}{l}\text { Richmond } \\
\text { (32 experiments, } \\
7307 \mathrm{~km} \text {, mean } \\
\text { epoch 1986.9) }\end{array}$ & $\begin{array}{l}\text { None } \\
\text { None } \\
\text { Model }\left(35^{\circ}\right) \\
\text { Model } \\
\text { Model } \\
\text { WVR }\left(20^{\circ}\right) \\
\text { WVR } \\
\text { WVR }\end{array}$ & $\begin{array}{l}\text { Bias } \\
\text { Markov } \\
\text { None } \\
\text { Bias } \\
\text { Markov } \\
\text { None } \\
\text { Bias } \\
\text { Markov }\end{array}$ & $\begin{array}{l}4.4 \pm 3.3 \\
4.4 \pm 3.3 \\
6.4 \pm 5.7 \\
4.4 \pm 3.6 \\
4.8 \pm 3.4 \\
5.6 \pm 3.1 \\
7.9 \pm 3.5 \\
6.8 \pm 3.3\end{array}$ & $\begin{array}{l}21.2 \\
21.2 \\
38.4 \\
23.0 \\
22.1 \\
20.6 \\
22.3 \\
21.5\end{array}$ \\
\hline $\begin{array}{l}\text { OVRO } \\
\text { (28 experiments, } \\
7914 \mathrm{~km} \text {, mean } \\
\text { epoch 1984.6) }\end{array}$ & $\begin{array}{l}\text { None } \\
\text { None } \\
\text { Model }\left(35^{\circ}\right) \\
\text { Model } \\
\text { Model } \\
\text { WVR }\left(20^{\circ}\right) \\
\text { WVR } \\
\text { WVR }\end{array}$ & $\begin{array}{l}\text { Bias } \\
\text { Markoy } \\
\text { None } \\
\text { Bias } \\
\text { Markov } \\
\text { None } \\
\text { Bias } \\
\text { Markov }\end{array}$ & $\begin{array}{r}12.9 \pm 2.7 \\
13.9 \pm 2.3 \\
9.8 \pm 3.0 \\
12.1 \pm 2.2 \\
13.6 \pm 2.2 \\
12.9 \pm 2.9 \\
13.0 \pm 1.8 \\
13.8 \pm 2.3\end{array}$ & $\begin{array}{l}36.6 \\
29.4 \\
39.7 \\
29.6 \\
29.2 \\
36.9 \\
23.4 \\
28.4\end{array}$ \\
\hline $\begin{array}{l}\text { GRAS } \\
\text { (73 experiments, } \\
7941 \mathrm{~km} \text {, mean } \\
\text { epoch 1986.2) }\end{array}$ & $\begin{array}{l}\text { None } \\
\text { None } \\
\text { Model }\left(35^{\circ}\right) \\
\text { Model } \\
\text { Model } \\
\text { WVR }\left(20^{\circ}\right) \\
\text { WVR } \\
\text { WVR }\end{array}$ & $\begin{array}{l}\text { Bias } \\
\text { Markov } \\
\text { None } \\
\text { Bias } \\
\text { Markov } \\
\text { None } \\
\text { Bias } \\
\text { Markov }\end{array}$ & $\begin{array}{l}10.5 \pm 2.2 \\
11.2 \pm 1.6 \\
12.0 \pm 1.9 \\
10.7 \pm 2.0 \\
11.2 \pm 1.6 \\
12.0 \pm 1.7 \\
11.7 \pm 1.5 \\
12.2 \pm 1.5\end{array}$ & $\begin{array}{l}38.8 \\
27.8 \\
33.1 \\
35.4 \\
27.6 \\
28.4 \\
25.9 \\
26.1 \\
\end{array}$ \\
\hline
\end{tabular}

aThe abbreviations used for the sites are OVRO: Owens Valley Radio Observatory (Owens Valley, California); GRAS: George R. Agassiz Station (Fort Davis, Texas).

${ }^{b}$ The a priori information used is either none, or the ground-based model, or the WVR. If an elevation cut-off angle is applied, its value is given in parentheses. If an atmospheric delay is estimated, it is assumed to be either a constant in the zenith direction (bias) or a Markov process.

${ }^{c}$ The standard deviations are scaled as described in the caption to Figure 5.

least affected by errors in our estimates of the Earth rotation parameters, is $3.3 \mathrm{~mm}$; of the east component, $6.9 \mathrm{~mm}$; and of the height, $20.1 \mathrm{~mm}$. The corresponding values for the WVR solution are 3.2, 7.0, and $22.2 \mathrm{~mm}$. Here we see no improvement in the repeatability of the estimates of the heights when the WVR data are used. The largest contrib- utor to the WRMS scatter for the WVR data is the single experiment in September 1987, for which the WVR data had large gaps due to rain. If this experiment is removed, then the WRMS scatter of height estimates from the WVR solution reduces to $20.4 \mathrm{~mm}$. In examining Figures 9 and 10 , we note that the Markov solutions have several experi- 


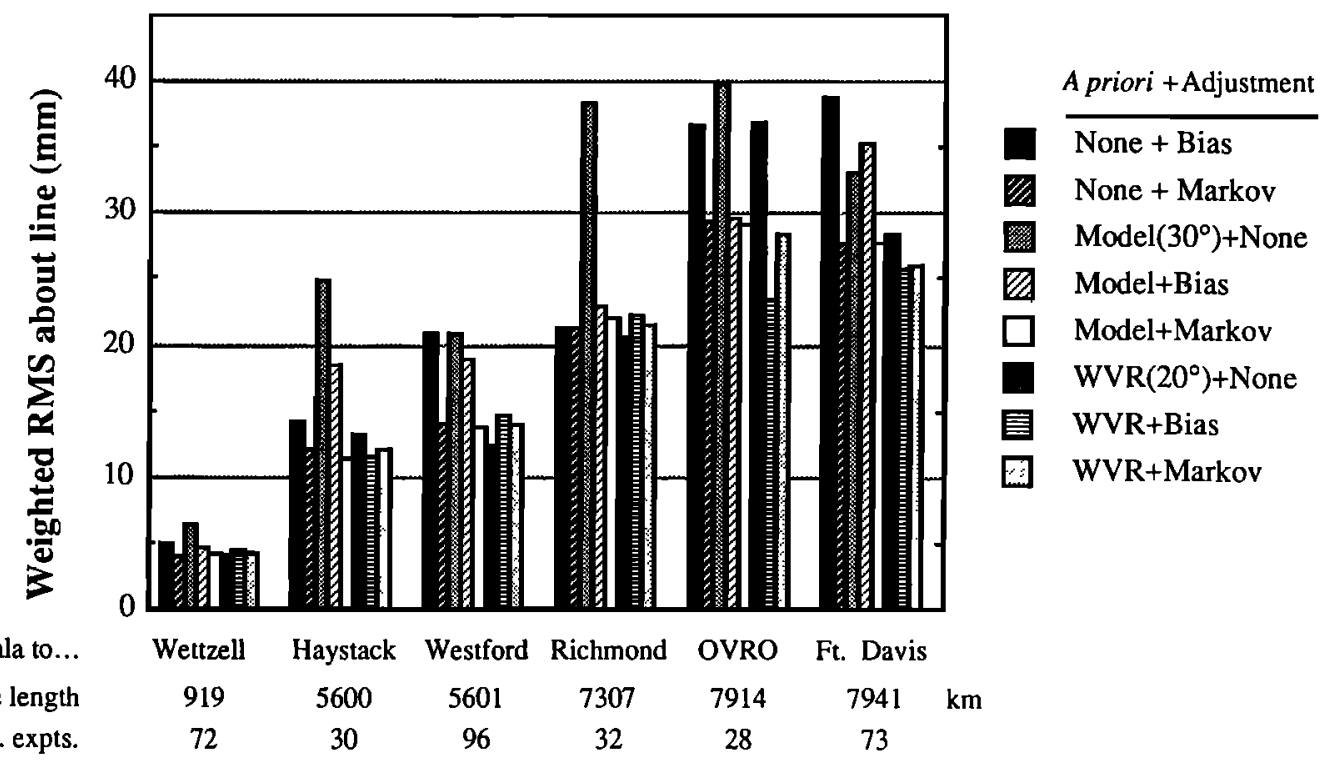

Fig. 8. WRMS scatters from Table 2 shown in graphical form (see Table 2 caption for detaile).

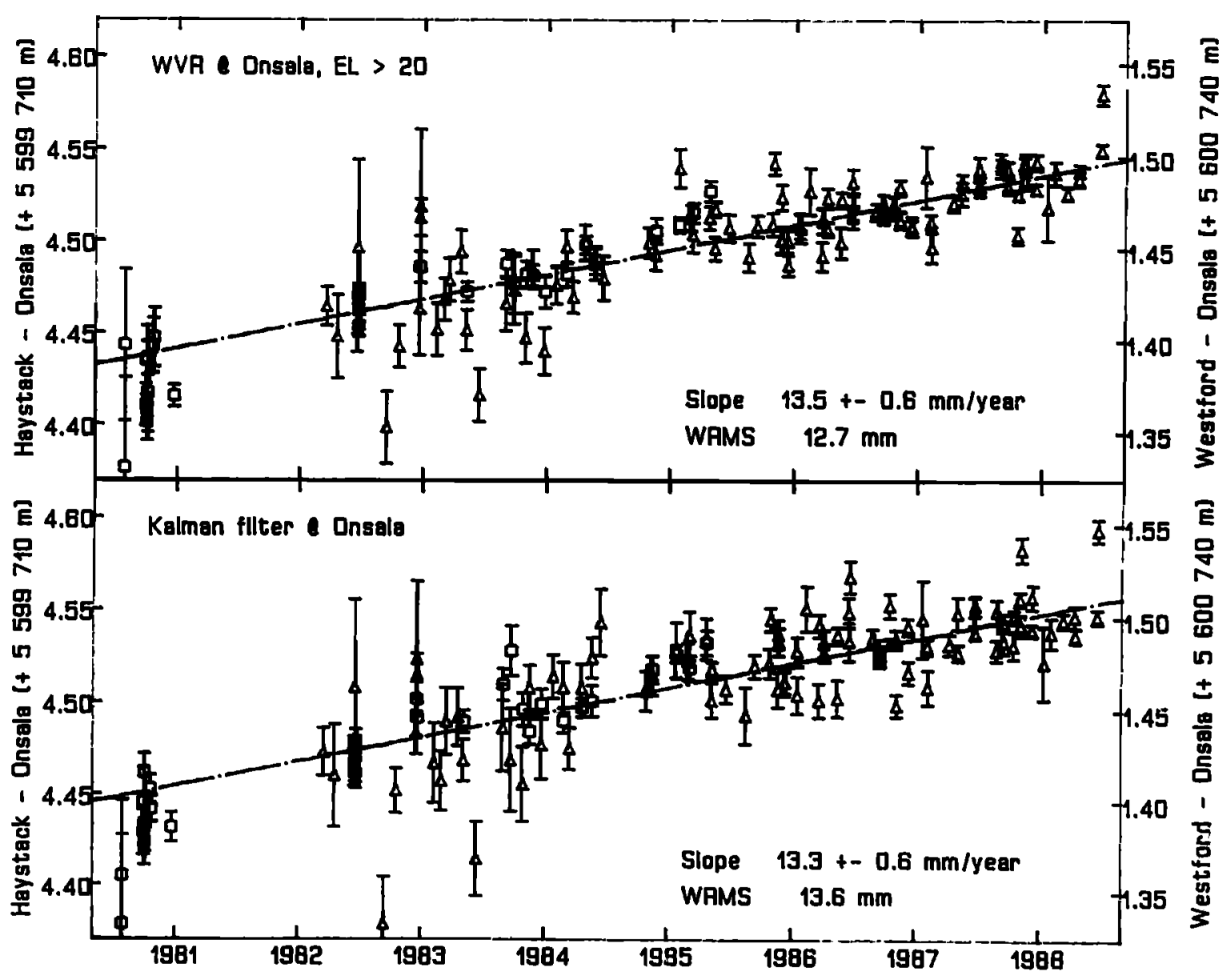

Fig. 9. Estimated baseline lengths from Onsala to the "combined" Haystack/Westford site. The circles denote measurements to Haystack, and the triangles denote measurements to Westford. Since both sites were involved in seven experiments simultaneously, there are 126 messurements all together. Both the statistical standard deviations for the individual experiments and the repeatability have improved with time. The following milestones should be noted. June 1982: The Mark-III system at Onsala was upgraded from 7 to 14 video converters, implying better group delay measurements. May 1985: Westford installed a cooled receiver and replaced Haystack in almost all CDP experiments. August 1986: Onsala installed a cooled receiver. March 1987: Onsala installed a dual-frequency feed in the $20-\mathrm{m}$ radome-enclosed telescope which previously was used for $X$ band observations only, with the $S$ band measurements having been obtained from a different nearby ( $<1$ km separation) antenna. 


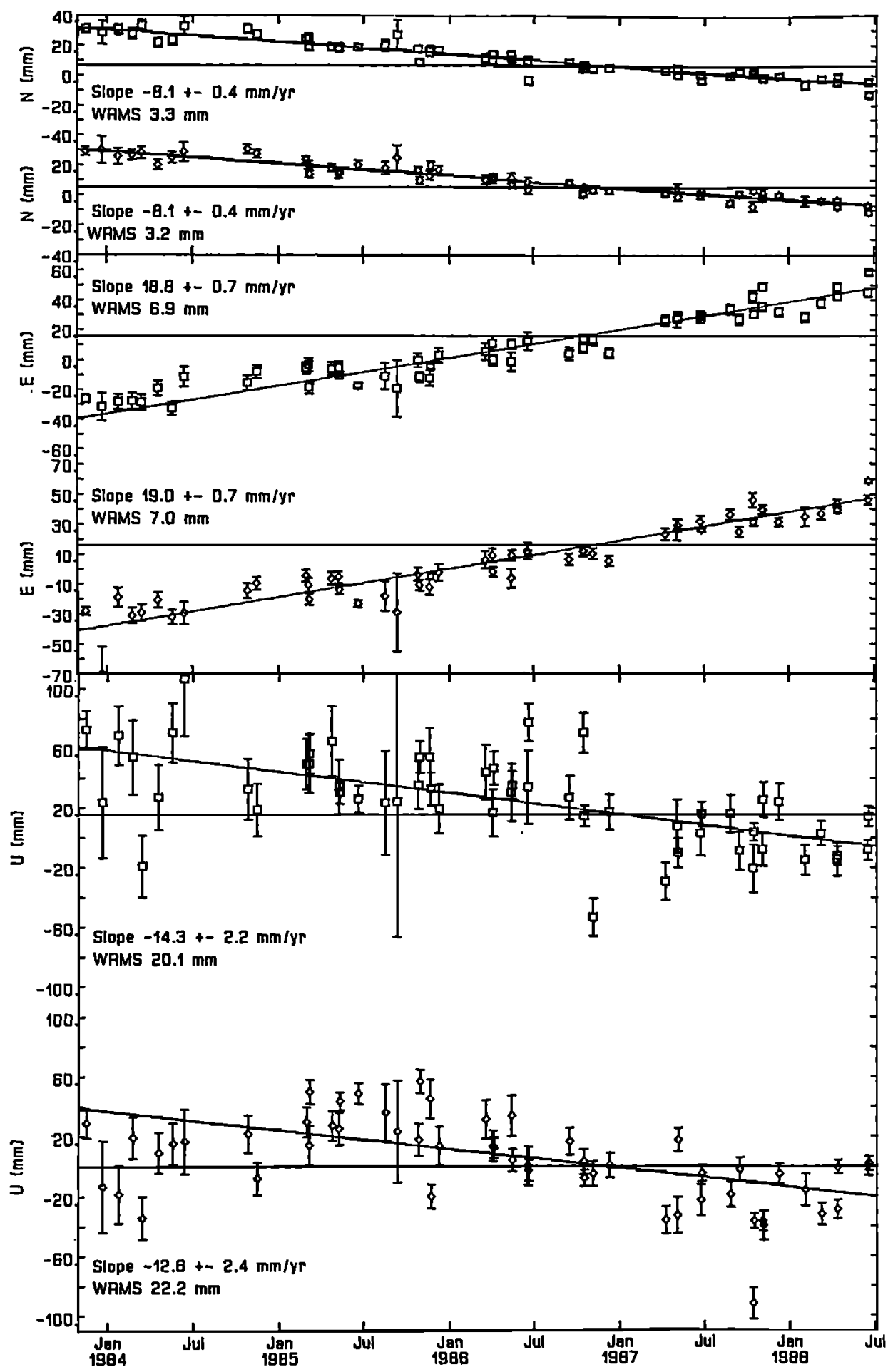

Fig. 10. Estimates of the coordinates of Onsala, in a North America fixed frame, in its local north (N), east (E) and up (U) frame obtained from the analysis of 24-hour VLBI experiments. The squares denote solutions which used stochastic estimation for the atmospheric delays at Onsala; the diamonds denote solutions which used WVR. data, excluded data below $20^{\circ}$ elevation angle, and did not estimate any atmospheric parameters. The results are given as linear displacements from an arbitrary location. The solid horizontal line within each group of estimates represents the weighted mean for that group.

ments with large residuals relative to their error bars; their counterparts for the WVR solution are not all anomalous. Also, some values are anomalous for the WVR solution but not for the Markov solution. These experiments are characterized by poor quality or aparse (due to rain, for example) WVR data. We have examined in detail some of the experiments that yielded the anomalous Markov results, especially those done in June and October 1987. The estimates of the heights from all of these experiments (Figure 10) show a large dependence on the minimum elevation 
angle of the Onsala data included in the solution: as low elevation angle data are removed, the estimates from solutions with and without atmospheric parameters estimated approach values consistent with the trend of the best fit straight line, but from opposite sides. The WVR solutions shown in this figure are not greatly affected by this characteristic because the data below $20^{\circ}$ elevation angle were not used. We interpret this behavior tentatively as being due to an error in the mapping function for the hydrostatic delays for these particular experiments. We are now undertaking a detailed study of some of these experiments so that we can gain a better understanding of the meteorological conditions which lead to such possible errors in the mapping functions.

There is a mean difference of $-17 \mathrm{~mm}$ (Markov minus WVR) in the heights estimated from the Markov and WVR solutions. This mean difference is consistent with the mean difference in the estimates of the baseline length between Westford/Haystack and Onsala and, presumably, arises from the same source which causes the 10-mm average zenith propagation delay bias between the WVR and Markov solutions discussed above (also see Figure 5). The relationship between the zenith propagation delay bias and the height difference is consistent with the source of the bias either being an actual bias in the calibration or an artifact of a (nearly constant) error in the mapping function for the hydrostatic delay.

\section{Discussion of GeOdetic Results}

The primary aim of this paper is to discuss estimates of the wet delay obtained from water vapor radiometry. However, there are apparently geophysical signals in the geodetic results we have presented which we now examine. The following brief discussion is our tentative interpretation of these results: there are still many issues we need to address before we will be satisfied that we fully understand these signals. A more complete discussion of these results and those from other sites will be given in a future paper.

Table 3 contains the VLBI estimates (see Figure 10) of the components of the vector velocity of Onsala compared with other estimates for the components of that vector. The VLBI estimates are from the WVR solutions (diamonds in Figure 10), but the following discussion is valid for the stochastic atmosphere solution as well. The estimates of the horizontal velocities are compared with those obtained from the global plate motion model NUVEL-1 (C. DeMets, personal communication, 1987). The estimate of the vertical velocity is compared with that obtained from estimates of postglacial rebound based on 100 years of sea level data [Ekman, 1989; M. Ekman, National Land Survey of Sweden, personal communication, 1989]. From Table 3, we can see that the horizontal motions are very close to those obtained from the global plate motion models, which treat the tectonic plates as rigidly moving on the surface of the Earth. We would expect this result, given that Onsala is located well into the interior of the Eurasian plate, far from zones of crustal deformation. But the estimate of the vertical velocity of Onsala differs significantly from the estimates of vertical rebound, which are nearly zero. We are studying the possibility that this apparent downward motion is being caused by an effect related to the atmospheric models. Perhaps relevant here is the origin of the $\approx 10 \mathrm{~mm}$ difference in zenith propagation delay between the WVR and Kalman filter solutions. But, given that this bias has been constant, with no apparent seasonal signatures, for over 8 years, it seems unlikely that its cause would also introduce a secular rate of change of height. Errors in modeling the mapping function for the hydrostatic delay could introduce time dependent biases in the estimates of height; however, the Markov and WVR solutions each showing about the same rate of change, despite these solutions having oppositely signed sensitivities to this type of error, seems to rule out this possibility. Thus, we have as yet no plausible source of systematic error that would account for the discrepancy.

The estimates of height from the WVR solution also show some unexpected systematic behavior, especially in 1984, when all of the estimates are below the trend of the best fit straight line. Given the sensitivity of this type of solution to errors in the calibrated zenith propagation delay, even with data below $20^{\circ}$ excluded from the solution, we were not able to attribute this behavior to actual changes in the motion of the site, especially since we do not see such pronounced behavior in the Markov solution, which is insensitive to errors in the a priori calibration of the zenith propagation delays. There are, however, other indications of temporal variations in the height of Onsala or in the source(s) of systematic error. The average rate of change of the Haystack/Westford-Onsala baseline prior to late 1984 was $17.4 \pm 1.7 \mathrm{~mm} \mathrm{yr}^{-1}$ for the Markov solution, a value consistent with that given by Herring et al. [1986], and consistent also with the value for the rate calculated from estimates of global plate motion velocity. The estimates after this date have an average rate of change of only $8.8 \pm 1.5 \mathrm{~mm} \mathrm{yr}^{-1}$. The corresponding rate estimates for the WVR solution are $18.3 \pm 1.9$ and $9.8 \pm 1.3 \mathrm{~mm} \mathrm{yr}^{-1}$. However, despite these large, consistent signals, we are certainly not convinced that these differences result from a

TABLE 3. Comparison of Velocity Components for Onsala, Sweden

\begin{tabular}{lrrr}
\hline Component & $\begin{array}{c}\text { VLBI Estimate, } \\
\mathrm{mm} \mathrm{yr}^{-1}\end{array}$ & $\begin{array}{c}\text { Other Estimate, } \\
\mathrm{mm} \mathrm{yr}^{-1}\end{array}$ & Source \\
\hline North & $-8 \pm 1$ & $-10 \pm 2$ & NUVEL-1 $^{b}$ \\
East & $19 \pm 1$ & $17 \pm 1$ & NUVEL-1 $^{b}$ \\
Up & $-14 \pm 2$ & $2 \pm 1$ & Sea level data \\
\hline
\end{tabular}

See text for definition of coordinate system.

a WVR solutions.

${ }^{6}$ From C. DeMets (personal communication, 1987).

'From Ekman [1989; personal communication, 1989]. 
change in the motion of Onsala, given the as yet incompletely understood systematic errors affecting our results. In particular, from this data set we cannot discount the possibility that the Westford site is responsible for the changing rate. However, a complete analysis of the VLBI data set, to be presented in a future paper, does seem to rule out this possibility.

\section{CONCLUSIONS}

WVR data and the Kalman filter estimation of the "wet" delay give comparable repeatability of estimated baseline lengths involving the Onsala VLBI site. We find from our data set that because of noise and calibration errors in the particular radiometer we used, the "best" elevation cut-off angle when data from this WVR are used is about $20^{\circ}$. The optimum elevation angle cut-off is set by a balance between the gain in the geometric "strength" of the baseline determination and the loss from the atmospheric "weakness" induced by defects either in the modeling or in the inferences from measurements of the atmospheric contributions to the group delays from the WVR data. We might expect a further improvement by designing experiments which obtained data from elevation angles above $20^{\circ}$ only, since then we would be throwing out no data. However, low elevation angle measurements are needed to obtain a better geometry for estimation of site position if atmospheric delays must be estimated [Davis et al., 1990]. Such estimates may be neceseary if, for example, a WVR is not available at a site or if it rains during a portion of an experiment, thus making the WVR data useless for our application. It is, therefore, of the greatest importance to minimize possible biases in the total atmospheric delay inferred from ground pressure measurements and WVR data so that data from observations at low elevation angles can be used without any bias degrading the accuracy.

Most of the results in this paper involve WVR data taken with one specific instrument operating in the specific climate of the Swedish west coast. Moreover, the daily variations in the wet delay at Onsala are expected to be smaller than those present at several other sites regularly used for geodetic VLBI. Since the uncertainties of the estimated parameters increase if a more variable wet delay is to be estimated by a Kalman filter (see Herring et al. [1990]), use of a more accurate WVR at a more humid site should yield larger improvements than those obtained in this study.

Given the repeatability obtained using the Kalman filter technique and the cost of a WVR, it may prove useful to have a WVR only at sites for which the expected wet delay variations are large. The WVR data can then also be used to check simultaneous Kalman filter estimates of the wet delay and to guard against other unmodeled errors in the VLBI data being absorbed into atmospheric delay estimates. However, since the Kalman filter technique is sensitive to mapping function errors, it may be necessary to use either a WVR or frequent radiosonde launches at each site to obtain the most accurate geodetic VLBI results.

Acknowledgments. We thank D.S. Robertson and T.H. Dixon for their thoughtful and constructive reviews. C.E. Kuehn performed the analysis of the J-03 WVR data obtained at Onsala in June and July 1988 and participated in the comparison of these data. This work was supported by the Air Force Geophyeics Laboratory, contract F-19628-86-K-0025; NASA grant NAG 5-538; NSF grant EAR-86-18989; and the Smithsonian Institution.

\section{REFERENCES}

Boudouris, G., On the index of refraction of air, the absorption and dispersion of centimeter waves by gases, J. Res. Natl. Bur. Stand, Sect. $D, 67,631-684,1963$.

Carter, W.E., D.S. Robertson, and J.R. MacKay, Geodetic radio interferometric surveying: Applications and results, J. Geophys. Res., 90, 4577-4587, 1985.

Chandrasekhar, S., Radiative Transfer, 393 pp., Dover, New York, 1960.

Chao, C.C., A model for tropospheric calibration from daily surface and radiosonde balloon measurements, Tech. Merm. 991-950, Jet Propulsion Lab., Pasadena, California, 1972.

Clark, T.A., B.E. Corey, J.L. Davis, G. Elgered, T.A. Herring, H.F. Hinteregger, C.A. Knight, J.I. Levine, G. Lundqvist, C. Ma, E.F. Nesman, R.B. Phillips, A.E.E. Rogers, B.O. Rönnäng, J.W. Ryan, B.R. Schupler, D.B. Shaffer, I.I. Shapiro, N.R. Vandenberg, J.C. Webber, and A.R. Whitney, Precision geodesy using the Mark-III very-long-baseline interferometer system, IEEE Thans. Geosci. Remote Sens., GE-2s, 438$449,1985$.

Coates, R.J., H. Frey, J. Bosworth, and G. Mead, Space-age geodesy: The NASA crustal dynamics project, IEEE Trass. Geosci. Remote Sens., GE-2s, 360-368, 1985.

Davis, J.L., T.A. Herring, I.I. Shapiro, A.E.E. Rogers, and G. Elgered, Geodesy by radio interferometry: Effects of atmospheric modeling errors on estimates of baseline length, Radio Sci., 20, 1593-1607, 1985.

Davis, J.L., T.A. Herring, and I.I. Shapiro, Effects of atmospheric modeling errors on determinations of baseline vectors from VLBI, J. Geophys. Res., in press, 1990.

Dicke, R.H., R. Beringer, R.L. Kyhl, and A.B. Vane, Atmospheric absorption measurements with a microwave radiometer, Phys. Rev., 70, 340-348, 1946.

Ekman, M., Impacts of geodynamic phenomena on systems for height and gravity, Bull. Geod, 69, 281-296, 1989.

Elgered, G., and $\mathbf{P}$. Lundh, $\mathbf{A}$ dual channel water vapor radiometer system, Res. Rep. 145, 17 pp., Chalmers University of Technology, Research Laboratory of Electronics and Onala Space Observatory, Onsala, Sweden, 1983.

Elgered, G., and G. Lundqvist, A three-year study of radio wave propagation delays due to tropospheric water vapor, IREE Thans. Antennas Propag. AP-se, 390-395, 1984.

Gary, B.L., S.J. Keihm, and M.A. Janssen, Optimum strategies and performance for the remote sensing of path delay using ground-based microwave radiometers, IEEE Thans. Geosci. Remote Serro., GE-2s, 479-484, 1985.

Goldstein, H., Attenuation by condensed water, in Propagation of Short Radio Waves, edited by D.E. Kerr, pp. 671-692, McGrawHill, New York, 1951.

Hauser, J.P., Effects of deviations from hydrostatic equilibrium on atmospheric corrections to satellite and lunar laser range measurements, J. Geophys. Res., 94, 10,182-10,186, 1989.

Herring, T.A., Precision of vertical position estimates from VLBI, J. Geophys. Res., 91, 9177-9182, 1986.

Herring, T.A., I.I. Shapiro, T.A. Clark, C. Ma, J.W. Ryan, B.R. Schupler, C.A. Knight, D.B. Shaffer, N.R. Vandenberg, H.F. Hinteregger, A.E.E. Rogers, J.C. Webber, A.R. Whitney, G. Elgered, G. Lundqvist, B.O. Rönnäng, B.E. Corey, and J.L. Davis, Geodesy by radio interferometry: Evidence for contemporary plate motion, J. Geophys. Res., 91, 8341$8347,1986$.

Herring, T.A., J.L. Davis, and I.I. Shapiro, Geodesy by radio interferometry: The application of Kalman filtering to the analysis of VLBI data, J. Geophys. Res., 95, 12,561-12,582, 1990.

Holton, J.R., An Introduction to Dynamic Meteonology, 2nd ed., 391 pp., Academic, San Diego, Calif., 1979.

Hopfield, H., Tropospheric effect on electromagnetically measured range: Prediction from surface weather data, Radio Sci., $6,357-367,1971$.

Janssen, M.A., A new instrument for the determination of radio path delay variations due to atmospheric water vapor, IEEE Thans. Geosci. Remote Sens., GE-29, 485-490, 1985.

Johansson, J.M., G. Elgered, and J.L. Davis, Geodesy by radio interferometry: Optimization of wet path delay algorithms using microwave radiometer data, Res. Rep. 152, 50 pp., Onsala Space Observatory, Chalmers University of Technology, Onsala, Sweden, 1987. 
Liebe, H.J., An update model for millimeter wave propagation in moist air, Radio Sci., 20, 1069-1089, 1985.

Liebe, H.J., A contribution to modeling atmospheric millimeter-wave properties, Frequenz, 11, 31-36, 1987.

Meeks, M.L., and A.E. Lilley, The microwave spectrum of oxygen in the Earth's atmosphere, J. Geophys. Res., 68, 1683$1703,1963$.

Reichert, G., Status of the SBF 78 water vapor radiometer, in Proceedings of the fth Working Group Meeting on European VLBI for Geodesy and Astrometry, edited by B.O. Rönnäng and G. Tang, pp. 32-36, Onsala Space Observatory, Onsala, Sweden, 1985.

Resch, G.M., Inversion algorithms for water vapor radiometers operating at 20.7 and $31.4 \mathrm{GHz}$, TDA Prog. Rep. 42-76, pp. 12-26, Jet Propulsion Laboratory, Pasadena, California, 1983.

Resch, G.M., M.C. Chavez, N.I. Yamane, K.M. Barbier, and R.C. Chandlee, Water vapor radiometry research and development phase final report, JPL Publ. 85-14, 122 pp., Jet Propulsion Laboratory, Pasadena, California, 1985.

Robineon, S.E., The profile algorithm for microwave delay estimation from water vapor radiometer data, Radio Sci., 23, 401-408, 1988.

Rosenkranz, P.W., Interface coefficients for overlapping oxygen lines in air, J. Quant. Spectrosc. Radiat. Transfer, s9, 287-297, 1988.

Saastamoinen, J., Atmospheric correction for the troposphere and stratosphere in radio ranging of satellites, in The Use of Artificial Satellites for Geodesy, Geophys. Monogr. Ser., vol. 15, edited by S.W. Henriksen et al., Pp. 247-251, AGU, Washington, D.C., 1972

Snider, J.B., and E.R. Westwater, Atmospheric attenuation at 15, 31, and $53 \mathrm{GHz}$, ESSA Tech. Rep. ERL 156-WPL 11, U.S. Department of Commerce, Boulder, Colorado, 1969.

Staelin, D.H., Measurements and interpretation of the microwave spectrum of terrestrial atmosphere near 1-centimeter wavelength, J. Geophys. Res., 71, 2875-2881, 1966.

Thayer, G.D., An improved equation for the radio refractive index of air, Radio Sci., 8, 803-807, 1974.

Waters, J.W., Absorption and emission by atmospheric gases, in Methods of Experimental Physics, vol. 12B, edited by M.L. Meeks, pp. 142-176, Academic, San Diego, Calif., 1976.

Wu, S.C., Optimum frequencies of passive microwave radiometer for tropospheric path-length correction, IEEE Trans. Antennas Propag., AP-27, 233-239, 1979.

J. L. Davis and I. I. Shapiro, Harvard-Smithsonian Center for Astrophysics, 60 Garden Street, Cambridge, MA 02138.

G. Elgered, Onsala Space Observatory, Chalmers University of Technology, S-439 00 Onsala, Sweden.

T. A. Herring, Massachusetts Institute of Technology, Cambridge, MA 02139.

(Received May 22, 1989;

revised March 27, 1990;

accepted April 5, 1990.) 